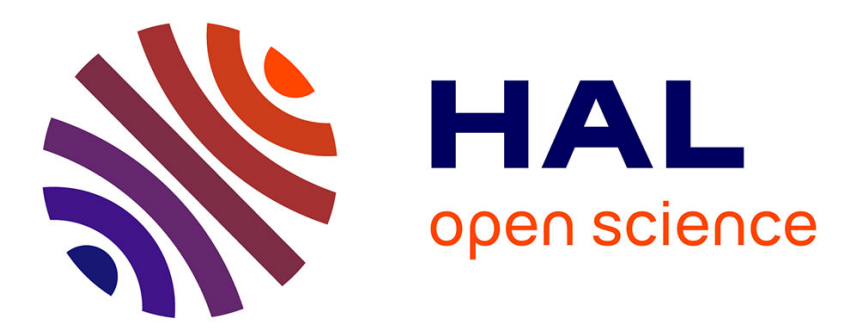

\title{
Manufacturability Assessment in the Conceptual Design of Aircraft Engines - Building Knowledge and Balancing Trade-Offs
}

\author{
Roland Stolt, Samuel André, Fredrik Elgh, Petter Andersson
}

\section{To cite this version:}

Roland Stolt, Samuel André, Fredrik Elgh, Petter Andersson. Manufacturability Assessment in the Conceptual Design of Aircraft Engines - Building Knowledge and Balancing Trade-Offs. 12th IFIP International Conference on Product Lifecycle Management (PLM), Oct 2015, Doha, Qatar. pp.407417, 10.1007/978-3-319-33111-9_38 . hal-01377467

\section{HAL Id: hal-01377467 \\ https://hal.inria.fr/hal-01377467}

Submitted on 7 Oct 2016

HAL is a multi-disciplinary open access archive for the deposit and dissemination of scientific research documents, whether they are published or not. The documents may come from teaching and research institutions in France or abroad, or from public or private research centers.
L'archive ouverte pluridisciplinaire HAL, est destinée au dépôt et à la diffusion de documents scientifiques de niveau recherche, publiés ou non, émanant des établissements d'enseignement et de recherche français ou étrangers, des laboratoires publics ou privés. 


\title{
Manufacturability assessment in the conceptual design of aircraft engines - building knowledge and balancing trade-offs
}

\author{
Roland Stolt ${ }^{1}$, Samuel André ${ }^{1}$, Fredrik Elgh ${ }^{1,}$ Petter Andersson ${ }^{2}$ \\ ${ }^{1}$ Department of Product Development, Jonkoping University, Jonkoping, Sweden \\ roland.stolt@jth.hj.se, samuel.andre@jth.hj.se, fredrik.elgh@jth.hj.se
}

${ }^{2}$ GKN Aerospace Sweden AB, Sweden
petter.andersson@gknaerospace.com

\begin{abstract}
This paper addresses the automated assessment of manufacturability of air-craft engine components in the early stages of design, focused on the welding process. It is a novel part of a multi-objective decision support tool for design evaluation, currently running at a manufacturer of jet engine components. The paper briefly describes the tool and how it impacts the product development process. Further, the paper presents an integrated method for manufacturability assessment by finding welding processes that complies with all geometrical and other constraints found in the CAD-models of the conceptual engine. Here, preferences made by manufacturing engineers serves as a base for a manufacturability index so that different parameter settings in the CAD-models can be compared to find the best parameter settings, considering the trade-off with other performance criteria's of the engine.
\end{abstract}

Keywords: Manufacturability, CAD, Robotic welding, Set-Based Concurrent Engineering, Multi-objective optimization.

\section{Introduction}

The aircraft engine industry needs to show an ever increasing performance in new products [1]. Today, cost and sustainability issues are much in focus for airline companies, so manufactures of aircraft engines must present products with reduced fuel consumption, less weight and less environmental impact and at the same time preferably to a reduced cost. Often, meeting the demands for increased performance is possible, however the price is that it becomes increasingly difficult to manufacture the products. The increased performance means higher temperatures and structural loads. To withstand the extra stresses more advanced alloys are needed and these are known to be notoriously difficult to process. Further, the geometries themselves tend to become more complicated with the increased demand on engine performance, due to e.g. optimization of the flow-path for lower pressure loss. 
For this reason it is desirable to have a good view on how well the design compiles with the intended manufacturing process in an early stage of design, so that decisions are not taken on a design that will turn out to be too expensive and difficult to manufacture.

To make these predictions, some of the details about the manufacturing process have to be known in the very early stages of design when principle solutions are discussed with the customer and the business contract is prepared. This will ensure that the manufacturability aspect is not left to a late stage in the design process, when the room for change is much less.

As described in this paper, the studied aircraft engine component manufacturer, evaluates conceptual designs in an early stage of product development considering the performance on structural, thermal and fluid-dynamical performance and assessment of geometrical tolerance distribution in a multi-objective manner. This is performed in an automated environment based on the CAD system Siemens NX. This environment is in this paper referred to as an integrated CAE (Computer Aided Engineering) environment. The environment allows studies of early designs by varying the parameters on surface CAD-models. Further, the CAE environment acts as a decision support tool, building knowledge on the effect of parameter settings of the conceptual models before it is progressed to detailed design. The tool is used to build knowledge and manage trade-offs which enables the company to support their knowledge value streams and to work with a set-based concurrent engineering approach.

The aircraft engine component manufacturer has a need to include more data for assessment of manufacturability in the studies in order to include more aspects of the product life cycle. It will be an early stage prediction on how suitable different parameter settings are from a manufacturability point of view. Thus, a trade-off can be made between the previously mentioned robustness, thermal, structural and fluiddynamical aspects and the manufacturability of the design. The automated approach that is applied when conducting the studies enables the company to work in a setbased manner, evaluating sets of solutions and parameter spaces.

One of the challenges is how to evaluate the manufacturability in a rapid way so that hundreds of different parameter variations on the same concept can be evaluated within a reasonable time. It must be done automatically in a short period of time.

Manufacturability refers to how a product can be produced to a minimal cost and at a maximal reliability. However, there are several influencing factors, as described by Vallhagen .et.al. [2]. Manufacturability can for instance refer to the complexity of the geometries, how well the different parts can me assembled, how difficult the materials are to form and so on [3, 4]. An automated evaluation based on CAD-models for all manufacturability aspects on the component is not expected to be feasible at the present time due to the many influencing factors. Therefore, to begin with, the most influential factors will be addressed and that is the welding of the structure. Several different methods for robotic welding are available in the workshop of the company and they all have different performance when it comes to which materials, geometries and thicknesses of plates that they can handle. The objective is to gain knowledge on the applicability and performance of the different methods in an early stage of design. How this is accomplished in a speedy automated way so that different parameter settings readily can be compared for manufacturability is the question that this paper will answer. The paper is a part of a larger research project which follows the Design 
Research Methodology (DRM) [5]. The companies involved in the project are actively participating in formulating success criteria and indicators as well as participating the descriptive and prescriptive phases.

\section{Platform definitions and set-based concurrent engineering}

Sub suppliers in industry are seeking ways to conduct product development in more efficient ways at the same time as offering highly customised products. A way to achieve efficient customisation is the use of a platform definition [6]. The component based product platform is often described as either modular or scalable. However, there will often be a demand for knowledge about future requirements and interfaces in order to create enough derivatives to gain back the extra expenses that has been put on developing the product platform. This creates issues for the sub suppliers developing products to be integrated in the customer's product where the interfaces and requirements is ever changing and unknown during development. One way to manage this is to extend the definition of a product platform to include more of the company assets than just highly concretised components [7]. Högman [8] explores the use of a technology platform that consist of methods which involves knowledge about the design and manufacture of the products. Levandowski et al. [9] uses the configurable component concept to model a platform in early stages of development. The modeling technique is based on set-based concurrent engineering (SBCE) and the hierarchy of functional requirements and design solutions. SBCE, opposed to a traditional point based approach, is a method where sets of solutions is developed in parallel [10]. In a point based approach a concept is chosen early in development and then iterated towards reaching a feasible solution. With SBCE a wider spectrum of the design space is explored. The focus is to eliminate bad or unfeasible solutions when enough knowledge about the solution exist as opposed to early picking a solution. Positive effects when applying SBCE has been observed in industry [11]. The knowledge value stream has been said to be, like SBCE, part of what has been coined lean product development. According to [12] the knowledge value stream consists of capturing and reuse of knowledge about markets, customers, technologies, product and manufacturing capabilities. The knowledge should be generalized and visualized to flow across projects and organizations.

This paper continue to build on the model first presented in [13]. If the design knowledge is captured, structured, saved and can be retrieved, it can be reused in future development project as a natural part of the platform definition. The continuous build-up of knowledge represented in the diagonal. Note that the knowledge build-up is ongoing while the PD projects have a start and an end. The knowledge gained is

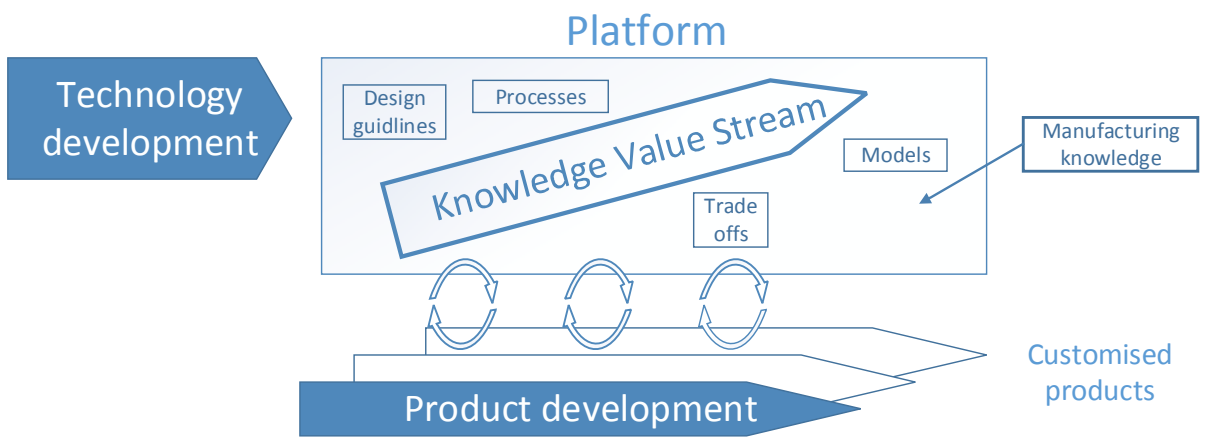

Fig. 1 Representing the knowledge to be re-used. 
reused in the PD projects. However, to realize this, it must be possible to find the knowledge and reuse it in a pre-planned way.

The knowledge can be represented in for example guidelines, process descriptions, models and best practice methods. There are also executables such as excel sheets, scripts and applications to facilitate the knowledge retrieval and possibly automated reuse. The Fig. 1 illustrates this frame-work. From the technology development new verified methods, tools and technology solutions emerges. The methods, tools and technology solutions are used in the different PD projects. Experiences from the products are used to refine and extend the platform.

This papers contribution lies in this context and consist of a representation of some of the manufacturing knowledge that is made available and adapted for the quick re-use. The paper is focused on the acquisition and automated re-use of this knowledge.

\subsection{Applied at the aeronautical company}

The company studied distinguishes clearly between the technological and product platform [13]. The company has a development process with the aim of developing methods and verifying them so that they can be included in the company's technology platform. To keep track of the readiness of the methods the TRL scale (Technology Readiness Level) developed by NASA is used. Examples of methods included in the technology platform can be regarding FEA and CFD analysis, explaining e.g. how the most appropriate type of mesh and how it should be applied and what type of elements should be used for the particular types of analysis.

Since the aeronautics industry have stiff demands on verification, it is not allowed to use any methods apart from the approved ones described in the technology platform.

When the aeronautical company is creating a new engine design (see Fig. 2) conceptual ideas are created together with the other suppliers of aero engines and components and the intended end costumers. This will give hints on what the expected requirements on the new generation of engines will be and which technologies that are expected to be used. Surface CAD-models of the concept is constructed. They are planned for variation of the parameters so that the design space can be covered without any update failures of the models.

To build knowledge on the effect of the parameter settings in the early stages of design, extensive automated parameter studies are made in the CAE environment. In the next step, the design is further elaborated with more precise simulations of the engines performance and including also detailed simulation of the production process. This includes e.g. offline-programming and path planning of the welding robots and the detailed sequencing and clamping of the sub-assemblies. The final stage is the testing and verification of the design which is made on physical parts. It is done first on a flying test-bench and eventually on the ready aircraft.

The studies in the CAE environment is done before any business contract has been

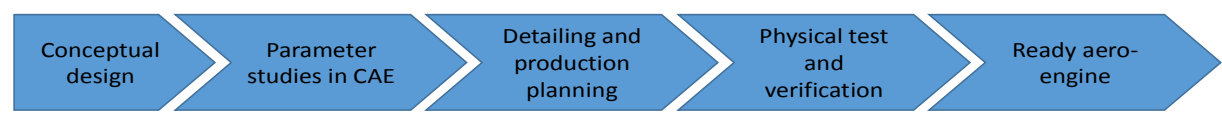

Fig. 2 The design of a new aero-engine. 
written. The main objective of the studies is to gain knowledge about the concept. Firstly, this will lead to that the trade-offs in the product are more thoroughly understood. It will also allow the manufacturer to respond quicker to changes when the contracts have be signed and the actual product development has begun. Often, as the development of the aircraft progresses the initial requirements change. Suppliers that can respond to these changes quickly are highly appreciated. It is therefore important for the supplier to continuously build up the general knowledge on the product and its manufacturing processes and just not focus on the development project closest at hand.

\subsection{CAE Environment}

The CAE environment operates automatically. This is necessary since the number of parameters varied is large and consequently requires a large number (in the order of hundreds) of experiments to evaluate the design space.

The CAE environment consists of scripts and other tailored methods for running all analysis in automated mode and also retrieving and visualizing the results.

The parameters that are varied are related to the material as well as the geometrical parameters such as lengths and angles. To some extent also the topology of the parts are also varied such as the number of stays in some structural parts.

These variants are later evaluated using FEA and CFD and tolerance simulation software from different aspects at the same time, forming a multi objective study. The objectives are the structural, thermal, geometrical robustness and the fluid-mechanical performance. Due to the high number of evaluations what must be done, the process of generating models and meshes with varying parameter settings and evaluating them is fully automated so that the results can be reviewed within a day or two.

\section{Working principle}

Manufacturability has traditionally been discussed from a machining point of view. Features in CAD models are identified interactively and automatically by feature recognition such that a process plan for their manufacture can be generated [14]. This process plan can form the basis of planning toolpaths and making predictions on the manufacturing costs.

However, evaluating manufacturability is not restricted to automated process planning of machining. Using MAS (Manufacturability Analysis System) [15] many other aspects of manufacturability can be analysed.

There have been numerous attempts on evaluation of geometries for weld processes to find the cost of welding a particular geometry represented in CAD. Some examples: [16], [17], [18]. These are based on the automated or interactive evaluation of CADmodels. Ordinary CAD models holds the geometrical information only, therefor this types of CAD models are often augmented with various manufacturing information. From the CAD-models process plans are created describing how much weld that will be needed and also the geometrical conditions in for example accessibility. From the planning of weld-methods and paths the weld-cost of welding can be calculated. 
The studies made in the CAE environment is done in the early stages of design. The studies are based on that number of CAD-models with different parameter settings are generated. Each such setting is called a "design case" For each design case the manufacturability is evaluated.

The objective in this early stage of design is not to get an absolute monetary value on the welding cost, but rather making a comparison between different design cases. One example of what the study is expected to reveal is that if the space is narrowed down in the vicinity of a weld, it will not be possible to access with the standard robotic weld gun. Therefore, selecting a less preferred weld-method will be necessary and thus lowering the manufacturability for that design case. Fig. 4 shows the different steps in the evaluation of a design case:

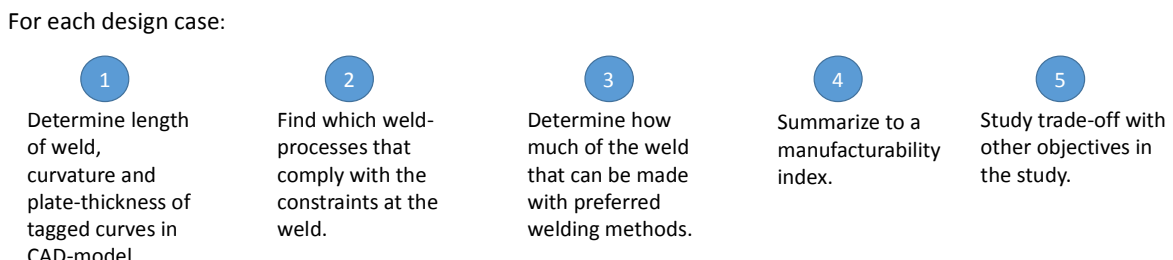

Fig. 4. The steps in evaluation of a design case.

Step1: All welds have been tagged with names when the CAD-model was created. This means that the model can be searched for all curves that represent welds by names. For each of the welds, the plate-thickness can be determined as well as the curvature in a number of points around the weld curve and the minimum distance to the nearest geometry (accessibility hindrance) from the weld in the $\mathrm{x}, \mathrm{y}$ and $\mathrm{z}$ directions with respect to the weld-head. The $\mathrm{z}$ direction is the longitudinal direction of the weldhead. Also the materials in the surfaces adjacent to the curve has been defined in the CAD-model and is read from it.

Products are typically built in sectors that are pre-assembled and subsequently welded together to circular geometries. Subassemblies can be either cast or fabricated i.e. assembled together from sheets of metal. Figure 5 below shows a CADmodel of one such sector with four weld-curves indicated by arrows.

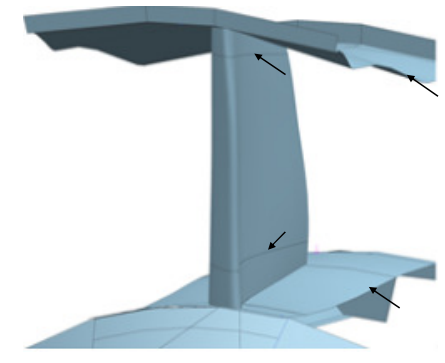

Fig. 3 A sector with some tagged welds indicated by arrows to be evaluated.

Step2: The conditions at the weld are compared with the capabilities and constraints of each weld-methods. The limitations for plate-thicknesses, curvatures, materials and reachability depends on what type of welding equipment that is used, the materials and the welding speed. To get an estimate on which plate-thicknesses that each weld method is capable of handling, the CES (www.grantadesign.com/products/ces/) is used. It gives the following ranges: EB 0,3 - $50 \mathrm{~mm}$, Laser 0,25 - 20mm, TIG 0,7 $8 \mathrm{~mm}$, Plasma 0,075 - $6 \mathrm{~mm}$. Since the limits includes extreme variants of the process encompassing all types of equipment, the ranges are narrowed down to exclude the extremes. The thickness-ranges are seen in table 1 below. 
The table 1 also show the minimum curvature, materials and the reachability. The reachability is derived from the sizes of commercially available weld-heads for robotic welding. The dimension in the z-direction is assumed to be $300 \mathrm{~mm}$ since small weld-heads can be found on the market corresponding to these dimensions. The dimensions in the $\mathrm{x}$ and $\mathrm{y}$ direction are about to $70 \mathrm{x} 70 \mathrm{~mm}$. Similarly, for robotic laser welding an estimate of the dimensions of the weld head is $(\mathrm{x}, \mathrm{y}, \mathrm{z})=(100,200$, $450 \mathrm{~mm}$ ) obtained from a supplier of such equipment.

In order not to get a too narrow section that can melt down and give a bad result there is a requirement on the curvature. This is expressed as a minimum radius related to the size of the weld pool. The size of the weld pool is much related to the process conditions, so no absolute values can be given in table 1 .

Table 1. Constraints per weld-process.

\begin{tabular}{|c|c|c|c|c|}
\hline \multicolumn{3}{|c|}{ Constraints per weld process: } & \multirow[b]{2}{*}{ erial } & \multirow[b]{2}{*}{ Rechability $x, y, z$} \\
\hline & Curvature & Plate-thickness & & \\
\hline Laser &.. & $1 \mathrm{~mm}-10 \mathrm{~mm}$ & \multicolumn{2}{|c|}{$\mathrm{Fe}, \mathrm{Al}, \mathrm{Ni}, 7100,200,450$} \\
\hline Electron beam & .. & $2 \mathrm{~mm}-30 \mathrm{~mm}$ & \multicolumn{2}{|c|}{$\mathrm{Fe}, \mathrm{Al}, \mathrm{Ni}, 1 .}$. \\
\hline TIG &.. & $1 \mathrm{~mm}-3 \mathrm{~mm}$ & $<$ list $>$ & $300,70,70$ \\
\hline Plasma & .. & $2 \mathrm{~mm}-8 \mathrm{~mm}$ & $<$ list $>$ & .. \\
\hline
\end{tabular}

For each weld, a subset of feasible welding methods is derived by examining which processes that comply with all constraints as seen in the below table 2 . The table shows that for weld 1 Laser and EB is possible. Weld 2 is not shown in detail in the table but feasible methods are Laser, EB and TIG.

Table 2. Finding feasible methods per weld.

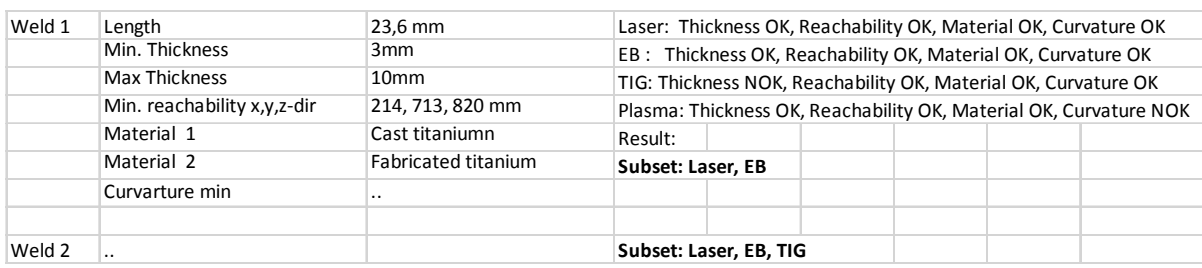

Step 3 and 4: When the subsets of feasible methods have been derived a selection of the most preferred ones must be made. This is done by means of a ranking for weld preference. This ranking list has been put together by the manufacturing engineers and assigns figures to the degree of preference. In the degree of preference, the cost and robustness of the method as well as its performance from a sustainability perspective is included. The ranking is the following: Laser welding is the most preferred with 15 points, TIG is the second best with 14 points, Plasma-welding has 12 points and finally EB welding has 10 points. This preference needs to be weighed together to a single figure on the manufacturability $(\mathrm{M})$ in percent. The model used considers how much of the total weld length can be made by the preferred method: 


$$
M=100 \cdot\left(\frac{L_{\text {Laser }}}{L_{\text {tot }}} \cdot \frac{P_{\text {laser }}}{P_{\text {highest }}}+\frac{L_{T I G}}{L_{\text {tot }}} \cdot \frac{P_{T I G}}{P_{\text {highest }}}+\frac{L_{\text {Plasma }}}{L_{\text {tot }}} \cdot \frac{P_{\text {Plasma }}}{P_{\text {highest }}}+\frac{L_{E B}}{L_{\text {tot }}} \cdot \frac{P_{E B}}{P_{\text {highest }}}\right)
$$

Thus a design case where all the welding can be made by laser welding will have manufacturability $100 \%$.

If it wasn't possible to use laser in the whole weld, say as an example that the constraints evaluation showed that out of $50 \mathrm{~m}$ weld, $30 \mathrm{~m}$ could be made by laser, 10 $\mathrm{m}$ could be made by TIG, $5 \mathrm{~m}$ by plasma, and $5 \mathrm{~m}$ by EB, the manufacturability would instead be $\mathrm{M}=93 \%$ :

$$
M=100 \cdot\left(\frac{30}{50} \cdot \frac{15}{15}+\frac{10}{50} \cdot \frac{14}{15}+\frac{5}{50} \cdot \frac{12}{15}+\frac{5}{50} \cdot \frac{10}{15}\right)=93 \%
$$

Step 5: Now the manufacturability is listed for every design case. All other aspects of the design case is considered at the same time. The below table 3 , shows the results of run. It has been simplified and it contains dummy figures. The table illustrates the multi objective nature of the run.

Table 3. Results of a run in the CAE environment.

\begin{tabular}{|c|l|l|l|l|l|}
\hline Design Case & $\begin{array}{l}\text { Expected Life in } \\
\text { hours }\end{array}$ & $\begin{array}{l}\text { Factor } \\
\text { buckling }\end{array}$ & Robustness & Pressure loss (bar) & Manufacturability \% \\
\hline 1 & 500 & 0,82 & $1 \%$ & 0,1 & 95 \\
\hline 2 & 520 & 0,83 & $1,3 \%$ & 0,3 & 93 \\
\hline 3 & 492 & 0,845 & $1,2 \%$ & 0,2 & 92 \\
\hline.. & & & & & \\
\hline
\end{tabular}

This forms a decision support, finding interesting settings of the parameters for the bests trade-offs in the design cases of the multi-objective study. Some of the more promising of them can be singled out for more detailed analysis. The results can be shown as surface plots such that a trade-off for the best parameter setting can be found.

\section{Discussion}

This paper describes the studied aerospace company's approach towards including manufacturability knowledge in a platform definition. The modelled manufacturability knowledge is described in a way that enables integration of an automated multi objective evaluation tool. With this approach a parameter space can be evaluated in an early stage exploring several concept sets. Knowledge about the designs are built and can be communicated. This supports both SBCE and the knowledge value stream in the company to a larger extent. The introduction of manufacturability evaluation has been performed with a subjective method, involving ranking by manufacturing engineers. The research is still in early phases and more elaboration on the influencing factors are expected to be done. The presented method 
does not include the assembly order and clamping of the parts to be welded. Also operations like cleaning the plates and casts, making inspections and doing rework when faulty welds has been found is not included although they contribute considerably to the manufacturing cost.

The accessibility is in practice a complex problem. The robot must be able to position the welding head without any part of the robot or tool colliding with the work-piece. This would normally require off-line programming, planning the path in detail and finding the most efficient path. However, to date this require a human operator and as mentioned earlier, that is not possible in this type of set based evaluation. Just checking the distance to nearest object may produce erroneous results. It is believed that the key to more precise prediction is to automatically generate process plans for each design case. These will contain influential items with high impact on the cost and sustainability. These items can then be assessed using well established methods for cost and sustainability evaluation such as LCA (Life Cycle Analysis) and LCC (Life Cycle Costing).

\section{Conclusions and future work}

The results from the study suggest that the use of a platform definition containing descriptions of knowledge for reuse purposes is a promising way forward. The results appears to be valid for other sub suppliers similar to the one described in this paper. In order to use a set-based approach, creating and analysing several designs, automation becomes crucial. Automated evaluation of manufacturability based on CAD-models has previously been extensively researched. However, this paper has highlighted the need of a quick and autonomous tool for early stage feasibility studies and process planning. Some initial steps has been taken but the continuation of the research needs to address making accessibility predictions without interactive path planning as well as sequencing the production process so that process plans can be automatically created. From these more detailed predictions of manufacturability as well as cost and sustainability estimation is expected to be made.

\section{Acknowledgments.}

The authors would like to thank GKN aerospace Sweden AB for providing a great environment and participating in the research. Also the authors express gratitude towards the Swedish Agency for Innovation Systems (VINNOVA) for partly financing this research.

\section{References}

1. Vallhagen, J., et al. A framework for producibility and design for manufacturing requirements in a system engineering context. 2013. Cranfield.

2. Vallhagen, J., et al., An Approach for Producibility and DFM-methodology in Aerospace Engine Component Development. Procedia CIRP, 2013. 11(0): p. 151156. 
3. Boothroyd, G., Product design for manufacture and assembly. 3rd ed.. ed, ed. P. Dewhurst and W.A. Knight. 2011, Boca Raton, Fl: CRC Press.

4. Bralla, J.G., Design for manufacturability handbook. 2. ed. J.G. Bralla., New York: McGraw-Hill. (1999)

5. Blessing, L.T.M., DRM, a design research methodology, ed. A. Chakrabarti, London: Springer.(2009)

6. Simpson, T.W., et al., Advances in Product Family and Product Platform Design: Springer.(2014)

7. Johannesson, H., Emphasizing reuse of generic assets through integrated product and production system development platforms. Advances in product family and product platform design: Methods \& application, p. 119-146.(2014)

8. Högman, U. and H. Johannesson. Technology development practices in industry. in ICED 11 - 18th International Conference on Engineering Design - Impacting Society Through Engineering Design. (2011)

9. Levandowski, C., D. Raudberget, and H. Johannesson. Set-Based Concurrent Engineering for Early Phases in Platform Development. in The 21st ISPE International Conference on Concurrent Engineering-CE2014. (2014)

10. Sobek II, D.K., A. Ward, J. K. Liker, Toyota's Principles of Set-Based Concurrent Engineering. Sloan Management Review, p. 67-83.(1999)

11. Raudberget, D., Industrial Experiences of Set-Based Engineering - Effects, results and applications, Göteborg: Chalmers reproservice.(2012)

12. Kennedy, M., K. Harmon and E. Minnock, Ready, Set, Dominate: Implement Toyota's Set-Based Learning for Developing Products and Nobody Can Catch You!, Richmond: Va: Oaklea Press.(2008)

13. André, S., et al., Managing Fluctuating Requirements by Platforms Defined in the Interface Between Technology and Product Development, in Advances in Transdisciplinary Engineering: Moving Integrated Product Development to Service Clouds in the Global Economy, IOS Press: Amsterdam. p. 424-433.(2014)

14. Shah, J.J., Parametric and feature-based CAD/CAM : concepts, techniques, and applications, ed. M. Mäntylä, New York: Wiley.(1995)

15. Shukor, S.A. and D.A. Axinte, Manufacturability analysis system: Issues and future trends. International Journal of Production Research, 47(5): p. 13691390.(2009)

16. Maropoulos, P.G., et al., An integrated design and planning environment for welding: Part 1: Product modelling. Journal of Materials Processing Technology, 107(1-3): p. 3-8.(2000)

17. Chayoukhi, S., Z. Bouaziz, and A. Zghal, Cost estimation of joints preparation for GMAW welding process using feature model. Journal of Materials Processing Technology, 199(1-3): p. 402-411. (2008)

18. Elgh, F. and M. Cederfeldt, Cost-based producibility assessment: analysis and synthesis approaches through design automation. Journal of Engineering Design, 19(2): p. 113-130.(2008) 